
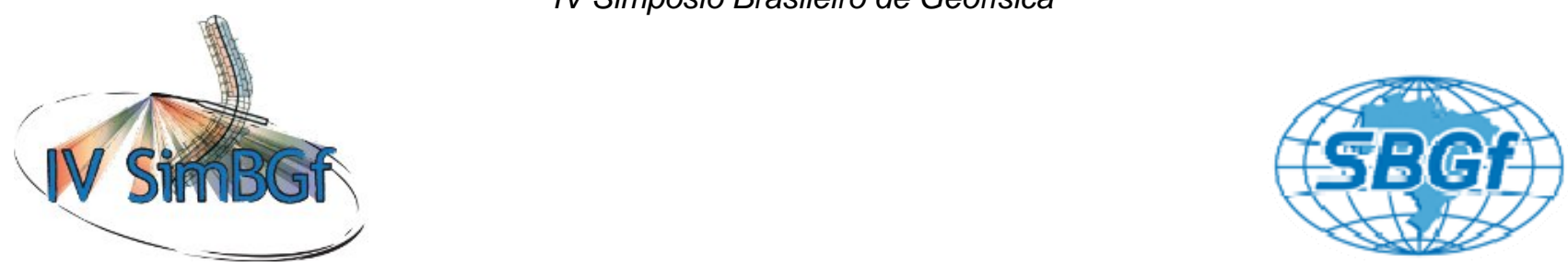

\title{
Levantamento magnetométrico em aterro de resíduos sólidos - Rincão dos Bitencourt, Município de Caçapava do Sul - RS.
}

Maura Motta Silveira*1, Fernanda Garcia ${ }^{1}$, Kathlem Melo ${ }^{1}$ e Maximilian Fries ${ }^{1}$.

${ }^{1}$ Universidade Federal do Pampa, Centro de Ciências Exatas e da Terra - Campus Caçapava do Sul

Copyright 2010, SBGf - Sociedade Brasileira de Geofísica

Este texto foi preparado para a apresentação no IV Simpósio Brasileiro de Geofísica, Brasília, 14 a 17 de novembro de 2010. Seu conteúdo foi revisado pelo Comitê Técnico do IV SimBGf, mas não necessariamente representa a opinião da SBGf ou de seus associados. É proibida a reprodução total ou parcial deste material para propósitos comerciais sem prévia autorização da SBGf.

\section{Abstract}

Solid waste deposition in improper places is one of the major concerns in the modern world. Considering the environmental pollution of soils and waters, indirect prospecting methods of investigation. Such magnetometry, allows a better understanding about the waste landfill deposit, its shape, depth and correlate with geologic structures that play a important role in the contamination pathways. This study presents a preliminary result obtained by magnetic survey, acquisition in a solid waste landfill area, located in the Caçapava do Sul city, southern part of the Rio Grande do Sul state, Brazil.

\section{Introdução e objetivos}

Diariamente são lançadas cerca de 200.000 toneladas de resíduos domésticos no meio ambiente, $96 \%$ tem o destino final em algum aterro não controlado. Isso acontece em 95\% das cidades do País, estas cidades possuem áreas comprometidas sem nenhum controle sanitário ou ambiental causando problemas como o aumento da poluição e a proliferação de doenças, insetos e mau-cheiro. Órgãos ambientais como - IBAMA (Instituto Brasileiro do Meio Ambiente) e a FEPAM (Fundação Estadual de Proteção Ambiental) trabalham na recuperação destas áreas junto com as prefeituras dos municípios.

Nos últimos anos a geofísica tem realizado vários estudos ambientais. No diagnóstico ambiental de áreas contaminadas, a aplicação de métodos geofísicos tem por objetivo básico a identificação de presença da contaminação subterrânea e seus limites, além da definição das feições geológicas/estruturais e hidrogeológicas dos locais investigados.

A metodologia aplicada consiste no levantamento magnetométrico aplicada em uma área de deposição de resíduos domiciliares, próximo a cidade de Caçapava do Sul, RS.

As principais etapas de desenvolvimento deste estudo preliminar são:
- Levantamento bibliográfico, digitalização e geração de mapas;

- Levantamento magnetométrico terrestre;

- Processamento dos dados;

- Mapa de isovalores com os valores magnetométricos de campo total;

\section{Localização da área e histórico}

A área de estudo localiza-se no município de Caçapava do Sul, situado a $255 \mathrm{~km}$ da cidade de Porto Alegre, na porção sul do Estado do Rio Grande do Sul, Brasil. O acesso da-sé pela Avenida Pedro Anunciação, Vila Batista ou pelo Forte Dom Pedro II(Figura 1).

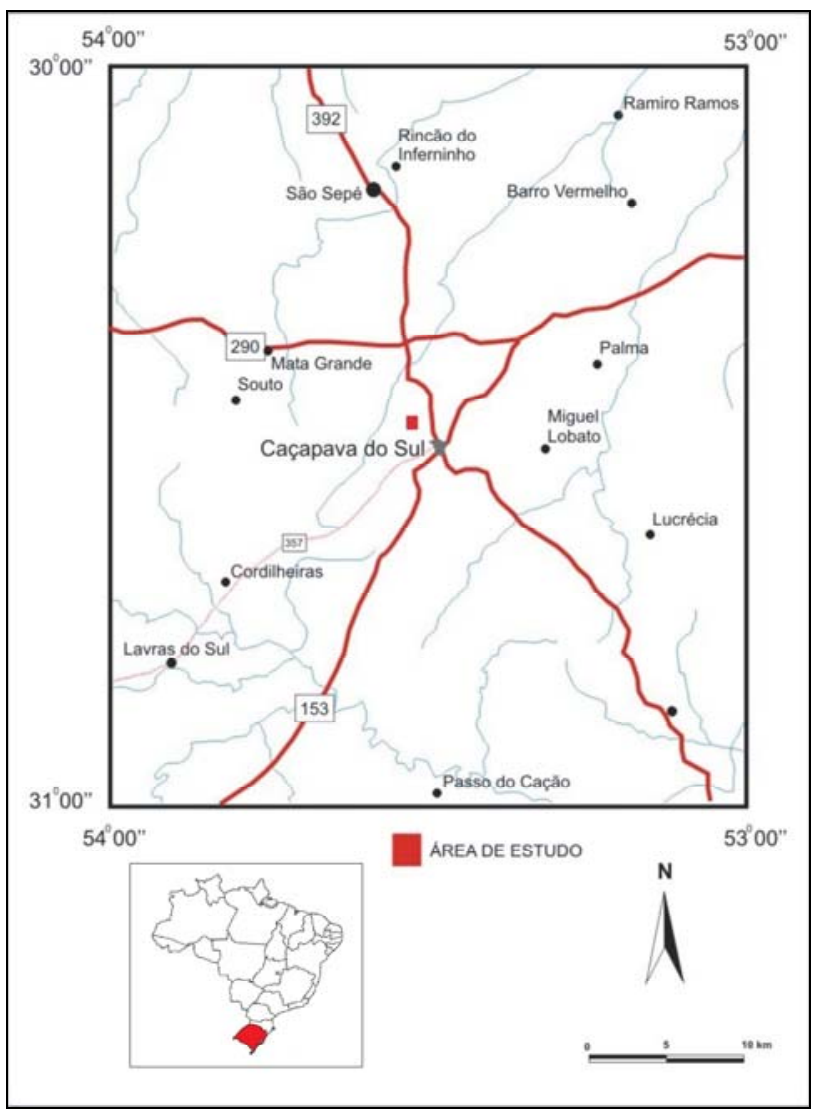

Figura 1 - Mapa de localização da área de estudo com as principais rodovias. 
Durante 14 anos, 28.000 toneladas de lixo urbano foram depositados em um local impróprio para esse fim, causando poluição no meio ambiente e transtorno aos moradores próximos a área através do aumento da população de insetos e mau-cheiro. A produção diária de chorume era grande ocorrendo poluição nos dois cursos de água que existem próximo a área. Em julho de 1994, a Prefeitura Municipal de Caçapava do Sul foi autuada pelo IBAMA que estabeleceu um prazo para a recuperação da área. Através das normas do IBAMA e da Metroplan em 11/09/1994 começaram os trabalhos de recuperação da área(PMC, 1994).

\section{Contexto geológico}

No contexto geológico regional a área é representada pelas rochas do embasamento, rochas vulcanosedimentares da Bacia do Camaquã e Sequência Metamórfica Vacacaí (Figura 2).

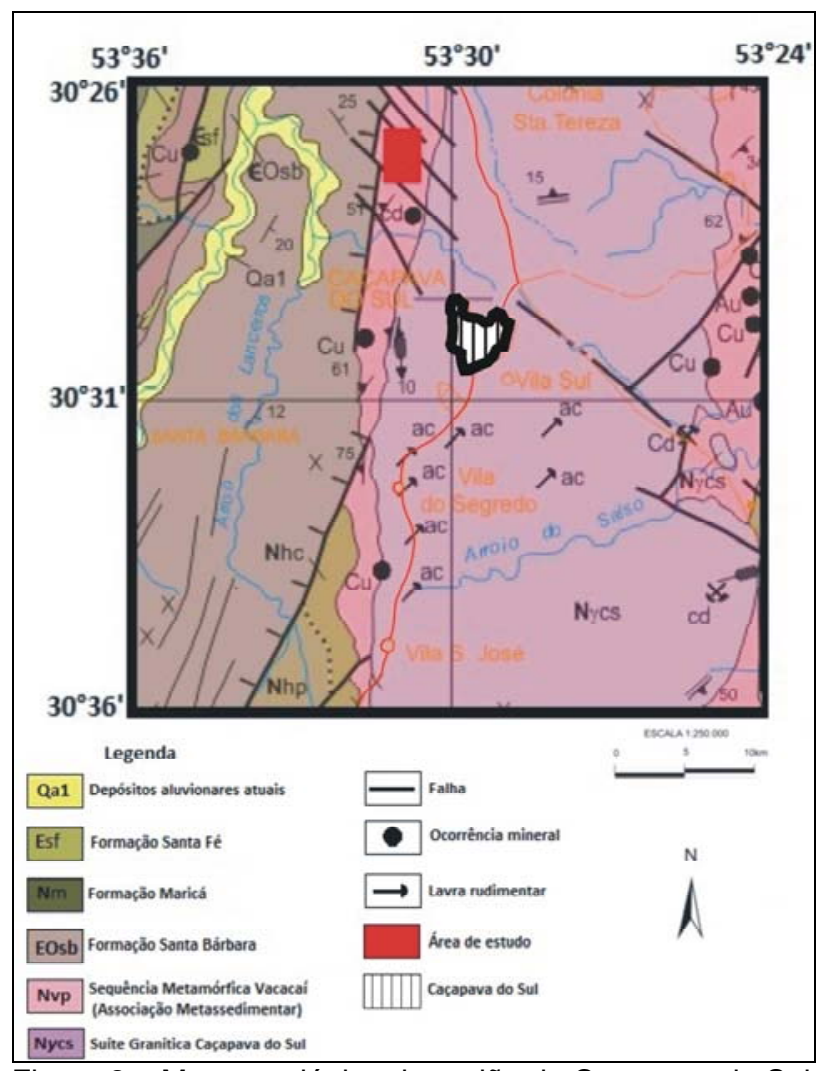

Figura 2 - Mapa geológico da região de Caçapava do Sul e principais unidades aflorantes na região (Modificado de Porcher, 2000b).

Denominação para designar associações de filitos, quartzitos, mármores, anfibólio xistos e clorita xistos, que juntamente com associações magnesianas agruparam no Grupo Porongos. Fragoso Cesar (1980) restringiu o termo Vacacaí às seqüências metamórficas de baixo a médio grau da porção oeste do escudo, reunindo metamorfitos vulcano-sedimentares e rochas básicoultrabásicas. Porcher (2000a) considera que na área abrangida pelo Folha Cachoeira do Sul (Figura 2), a Sequência Metamórfica Vacacaí é constituída por duas associações:1)rochas metassedimentares, anteriormente agrupadas no Complexo Passo Feio (Bitencourt, 1983) e na Sequência Metamórfica Arroio da Porteira; e 2) rochas vulcânicas metamorfizadas, localmente denominadas de Sequência Campestre (Koppe et al.,1985) e Pillow Lavas do Arroio Mudador (Macedo et al.,1978).

\section{Metodologia}

Foram adquiridas, até o momento, um total de 288 estações magnetométricas terrestres (Figura 3). As leituras magnéticas das estações levantadas foram obtidas através de um magnetômetro de precessão de prótons da GEM Systems Inc, modelo GSM - 19T. As estações foram medidas com um espaçamento de cinco metros ao longo de onze perfis de caminhamento com distância de dez metros, os perfis foram previamente realizado no estudo de Oliveira, 2010. As coordenadas horizontais ( $X$ e $Y$ ) para navegação e localização geográfica das estações foram determinadas usando-se um GPS portátil de mão.

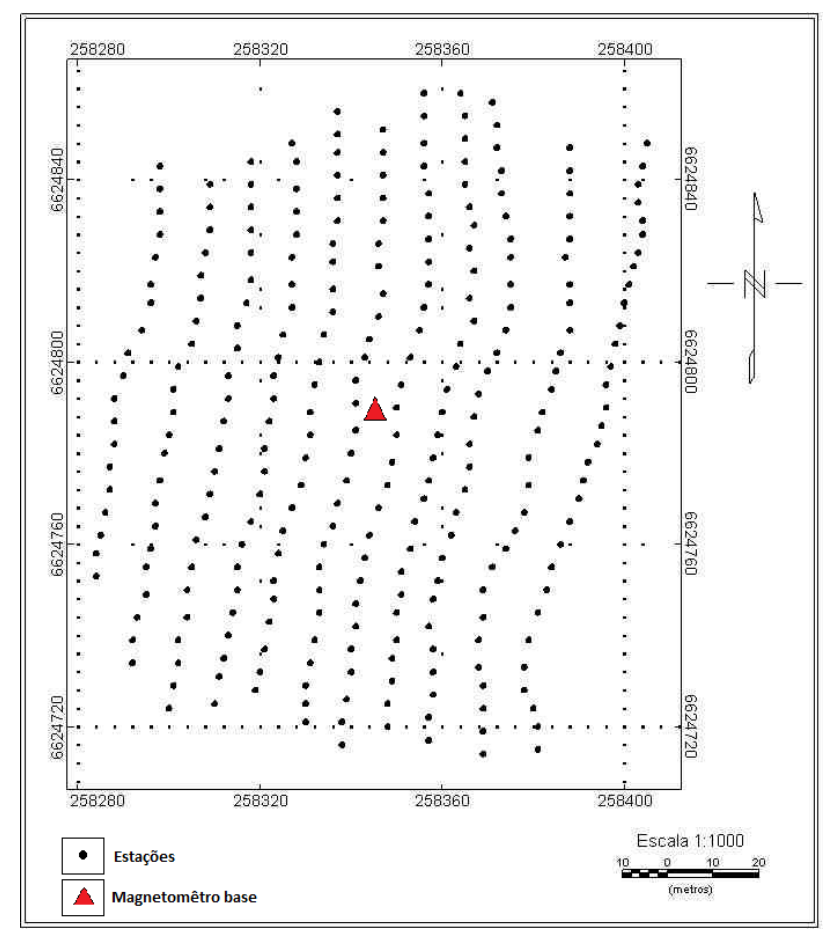

Figura 3 - Mapa com as estações magnetométricas na área do aterro de resíduos sólidos adquiridas até o presente momento.

\section{Características do mapa magnetométrico de campo total}

O mapa magnetométrico de campo total é produto de um grid gerado por interpolação pelo método da mínima curvatura. O grid é composto por $64 \times 77$ pontos (direções $X$ e $Y$ respectivamente), com uma separação 
da malha de 2 metros. Os valores interpolados no grid permitem a geração de um mapa de cores com os respectivos isovalores das anomalias magnéticas apresentadas. A base de dados com as estações magnetométricas, coordenadas, dados das anomalias magnéticas e o mapa de contorno, foram elaborados por rotinas próprias no software OASIS/MONTAJ comercializado pela Geosoft Inc.

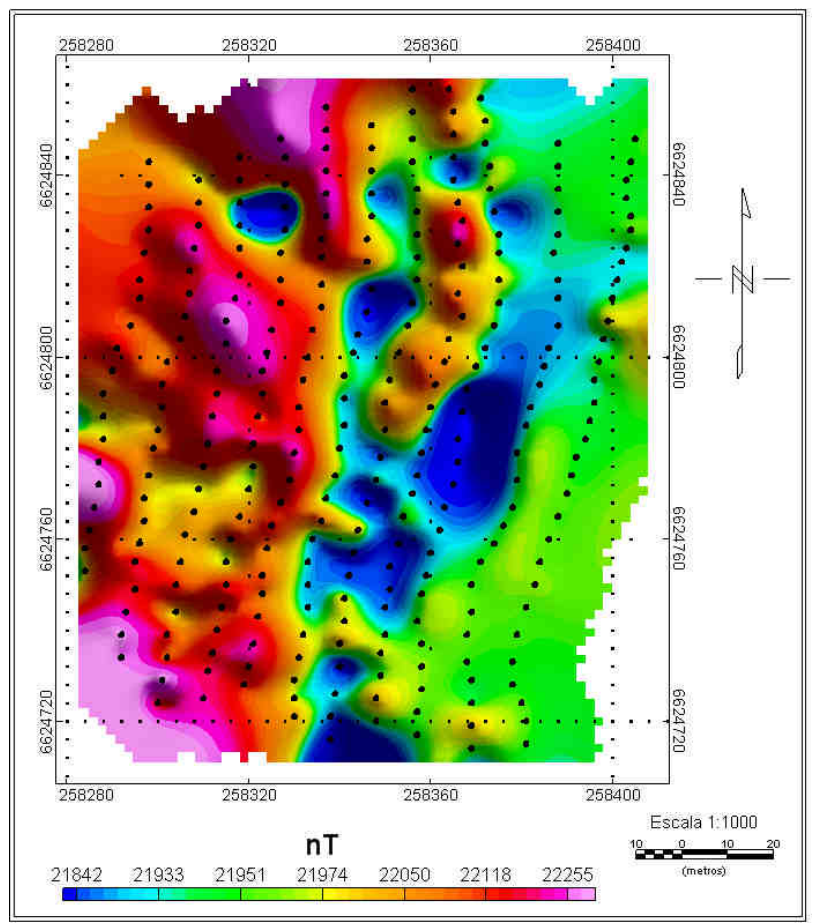

Figura 3 - Mapa de contorno sombreado com os dados magnéticos de campo total.

\section{Discussão e Conclusões}

O mapa magnetométrico com os valores do campo magnético anômalo total permite, de forma preliminar, observar valores anômalos com variações entre 21842 a $22255 \mathrm{nT}$, ao longo de toda a área. Pode-se analisar que a área possui valores de anomalia nos quadrantes NW e SW, consistindo, desta forma, em uma faixa com um limite contrastante que estende-se na direção N-S por toda área. Nos quadrantes $\mathrm{NO}$ e $\mathrm{SO}$, os valores da anomalia magnética encontram-se entre 21842 a 21974 $\mathrm{nT}$. As anomalias observadas permitem concluir a existência de uma região de deposição de resíduos localizada eu uma provável cava que estendia-se em toda faixa oeste da área. O estudo carece, no entanto, de maior detalhamento e analise integrada com dados geológicos, estruturais e modelagem dos dados observados.

\section{Agradecimentos}

Os autores agradecem o auxílio prestado pelo acadêmico Lenon Ilha, nas aquisições magnetométricas na área estudada. A acadêmica Mônica Teixeira pela colaboração na navegação e localização por GPS das estações magnetométricas e ao professor doutor César Moreira que possibilitou o conhecimento e acesso aos dados de localização dos perfis geoelétricos previamente adquiridos.

\section{Referências}

BITENCOURT, M. de F. Metamorfitos da Região Caçapava do Sul, RS - Geologia e Relações com o Corpo Granítico. In: SIMPÓSIO SUL-BRASILEIRO DE GEOLOGIA, 1, Porto Alegre, 1983. Atas... Porto Alegre:SBG, 1983. p. 37-49.

FRAGOSO CESAR, A.R.S. O Cráton Rio de La Plata e o Cinturão Dom Feliciano no Escudo Sul-Riograndense.In: CONGRESSO BRASILEIRO DE GEOLOGIA, 31 Balneário Camboriú, 1980. Anais... Florianópolis: SBG, 1980. v. 5, p.2679-2692.

GEM SYSTEMS - GSM 19 v 7.0 Instruction manual, http://www.gemsys.ca.

GEOSOFT INCORPORATED. 1999. Montaj MAGMAP filtering; $2-D$ frequency domain of potential field data extension for Oasis Montaj v.6.1. Toronto, Ontario, Canadá.

KOPPE, J.C.; HARTMANN, L.A.; LISBOA, P.F.C.; MONTEIRO, R.N. Aspectos geológicos e estratigráficos do Complexo Bossoroca, São Sepé - RS. Simpósio Sul Brasileiro de Geologia, 2, Florianópolis, 1985. Atlas. Florianópolis: SBG, 1985. P.32-36.

MACEDO, P.M.; BECKEL, J.; SANTOS, E.L.; CHABAN, N.; GONZALES FILHO, F. Ocorrência de Pillow-Lavas no Arroio Mudador, município de Caçapava do Sul - RS. In: CONGRESSO BRASILEIRO DE GEOLOGIA, 30, Recife, 1978. Anais... Recife: SBG, 1978. v. 3, p.1268-1278.

OLIVEIRA, Mônica Teixeira de; Aplicação integrada de métodos geoelétricos em área de disposição de resíduos sólidos domiciliares no município de Caçapava do Sul. Trabalho de Conclusão de Curso, UNIPAMPA, Caçapava do Sul, 2010.

PORCHER, Carlos Alfredo; LOPES, Ricardo da Cunha. Relatório folha Cachoeira do Sul SH.22 - Y - A: 2000a. Porto Alegre. 147p. 
PORCHER, Carlos Alfredo; LOPES, Ricardo da Cunha. Cachoeira do Sul, folha SH.22 - Y - A. Porto Alegre: CPRM, Programas Levantamentos Geológicos Básicos do Brasil, 2000b. Escala 1: 250.000.

PREFEITURA MUNICIPAL DE CAÇAPAVA DO SUL (Brasil). Relatório Secretária Municipal do Meio Ambiente. 1994. Caçapava do Sul, RS.

TELFORD, W.M.; GELDART, L.P.; SHERIFF, R.E. \& KEYS, D.A. 1976. Applied Geophysics. Cambridge: Cambridge University, 860p. 